\title{
Are cardiovascular risk factors also associated with the incidence of atrial fibrillation?
}

\section{A systematic review and field synopsis of 23 factors in 32 population-based cohorts of 20 million participants}

\author{
Victoria Allan'; Shohreh Honarbakhsh²; Juan-Pablo Casas; Joshua Wallace'; Ross Hunter²; Richard Schilling²; Pablo Perel³; \\ Katherine Morley4; Amitava Banerjee ${ }^{1}$; Harry Hemingway ${ }^{1}$ \\ ${ }^{1}$ Farr Institute of Health Informatics Research, Institute of Health Informatics, University College London, London, UK; ${ }^{2}$ The Barts Heart Centre, St Bartholomew's Hospital, Barts \\ Health NHS Trust \& Queen Mary, University of London, London, UK; ${ }^{3}$ Centre for Global Non Communicable Diseases, London School of Hygiene \& Tropical Medicine, London, UK; \\ ${ }^{4}$ Institute of Psychiatry, Psychology \& Neuroscience, Kings College London, London, UK
}

\begin{abstract}
Summary
Established primary prevention strategies of cardiovascular diseases are based on understanding of risk factors, but whether the same risk factors are associated with atrial fibrillation (AF) remains unclear. We conducted a systematic review and field synopsis of the associations of 23 cardiovascular risk factors and incident $A F$, which included 84 reports based on 28 consented and four electronic health record cohorts of 20,420,175 participants and 576,602 AF events. We identified 3-19 reports per risk factor and heterogeneity in AF definition, quality of reporting, and adjustment. We extracted relative risks (RR) and $95 \%$ confidence intervals $[\mathrm{Cl}]$ and visualised the number of reports with inverse $(\mathrm{RR}[\mathrm{Cl}]<1.00)$, or direct $(\mathrm{RR}[\mathrm{Cl}]>1.00)$ associations. For hypertension (13/17 reports) and obesity (19/19 reports), there were direct associations with incident $\mathrm{AF}$, as there are for coronary heart disease (CHD). There were inverse associations for non-White ethnicity (5/5 re-
\end{abstract}

Correspondence to:

Prof. Harry Hemingway

Farr Institute of Health Informatics Research

University College London, 222 Euston Road

London NW1 2AD, UK

Tel.: +44 2035495329

E-mail: h.hemingway@ucl.ac.uk ports, with RR from 0.35 to 0.84 [0.82-0.85]), total cholesterol (4/13 reports from 0.76 [0.59-0.98] to 0.94 [0.90-0.97]; 8/13 reports with non-significant inverse associations), and diastolic blood pressure (2/11 reports from 0.87 [0.78-0.96] to 0.92 [0.85-0.99]; 5/11 reports with non-significant inverse associations), and direct associations for taller height (7/10 reports from 1.03 [1.02-1.05] to 1.92 [1.38-2.67]), which are in the opposite direction of known associations with CHD. A systematic evaluation of the available evidence suggests similarities as well as important differences in the risk factors for incidence of $A F$ as compared with other cardiovascular diseases, which has implications for the primary prevention strategies for atrial fibrillation.

\section{Keywords}

Atrial fibrillation, risk factors, primary prevention, clinical guidelines, cardiovascular disease

\section{Financial support:}

This work was supported by the 10 funders of the Farr Institute of Health Informatics Research: The Medical Research Council (MRC) [K006584/1] in partnership with Arthritis Research UK; the British Heart Foundation; Cancer Research UK; the Economic and Social Research Council; the Engineering and Physical Sciences Research Council; the National Institute for Health Research; the National Institute for Social Care and Health Research (Welsh Assembly Government); the Chief Scientist Office (Scottish Government Health Directorates); and the Wellcome Trust, as well as the MRC PROGnosis RESearch Strategy Partnership [G0902393]. The study funders had no role in the study design; in the collection, analysis, and interpretation of data; in the writing of the report; and in the decision to submit the article for publication.

Received: November 2, 2016

Accepted after major revision: February 2, 2017

Epub ahead of print: February 23, 2017

https://doi.org/10.1160/TH16-11-0825

Thromb Haemost 2017; 117: 837-850

Supplementary Material is available online at www.thrombosis-online.com.

\section{Introduction}

Atrial fibrillation (AF) is the world's most common heart rhythm disorder, affecting 33.5 million people globally in 2010 (1). AF accounts for 1 in 4 ischaemic strokes (2), doubles the risk of death (3), places an economic burden on healthcare systems (4), and is projected to affect twice as many people by $2050(5,6)$. Yet to date, there have been no clinical trials of healthy participants without cardiovascular disease (CVD), and with AF as the primary outcome (7). The focus of trials has instead been on prevention of stroke and thromboembolism after diagnosis of AF. Community screening programmes for detection of $\mathrm{AF}$ (8), are also designed to identify patients at high risk of stroke and thromboembolism, and do not identify those who are at an initially high risk of later devel- 
oping AF. Thus, current clinical guidelines make no recommendations for the primary prevention of AF itself, among people without CVDs (9-11).

Established primary prevention strategies of other CVDs, such as coronary heart disease (CHD) (12), and stroke (13), are based on understanding of risk factors, but the extent to which the same risk factors are associated with the incidence of $\mathrm{AF}$ is not fully understood. Ultimately, it is not known whether existing CVD prevention strategies can also work in preventing $\mathrm{AF}$, or whether there may be important clinical differences. In synthesising available evidence the conventional (near universal) approach is to examine risk factors one at a time. Single risk factor systematic reviews and meta-analyses have been carried out for alcohol (14-16), C-reactive protein (17), diabetes mellitus (18), obesity (19), physical activity $(20,21)$, and renal function (22) in relation to AF risk. Each of these reviews uses non-identical methods, for example varying in the extent to which incident $\mathrm{AF}$ is analysed among people free from pre-existing CVD. While there is an important ongoing role for the vertical approach of a single risk factor meta-analysis (particularly if methods can be aligned), there is also a complementary role for a horizontal 'field synopsis' approach across multiple potential risk factors. The term field synopsis is defined as a systematic evaluation of evidence in which the i) overall amount, ii) extent of replication, and iii) protection from bias is considered across the whole field $(23,24)$. One advantage of a field synopsis in multifactorial diseases is to provide an unbiased empirical basis for prioritising further research into risk factors with preventive potential.

We therefore conducted a systematic review and field synopsis of the associations of a wide range of demographic, behavioural, and biological CVD risk factors and incidence of AF in general populations and populations initially free from diagnosed CVD. Field synopses' of cumulative evidence $(23,24)$, are common in genetics but have seldom been applied in the context of preventive medicine. Our objectives were i) to determine the amount of evidence for each risk factor, ii) to evaluate the extent to which each risk factor shows concordant or discordant associations with $\mathrm{AF}$ incidence across independent study populations, and iii) to systematically appraise the quality of the observational evidence across the field of AF prevention research.

\section{Methods}

Our approach to the search, selection, data collection and analysis of reports was systematic, and guided by the Preferred Reporting Items for Systematic reviews and Meta-Analyses (PRISMA) checklist (25).

\section{Search strategy}

We queried the PubMed database using the search terms listed in the Appendix p 3, for original research reports that were published in English up to October 1, 2015; involving prospective, population based cohorts that were either initially free from diagnosed
CVD at baseline or were general population cohorts in which the proportion of people with diagnosed CVD at baseline was low reflecting prevalence in the general population. Cohorts were of any age, and without prior AF; and investigated the association between "risk factors" and incident AF, over any follow-up period, and using Cox proportional hazards or Poisson regression models adjusted or stratified for age and sex as a minimum. We shortlisted 23 cardiovascular risk factors (listed in $>$ Table 1) for review, based on clinical relevance as an established predictor or treatment target in the prevention of CVD (12), or on clinical opinion of an association with AF (9), and on expert consensus between authors. Reference lists of identified reports, existing reviews and meta-analyses (which were not restricted to prospective cohorts of individuals either free from or with general population levels of baseline CVD: alcohol (14-16), C-reactive protein (17), diabetes mellitus (18), obesity (19), physical activity $(20,21)$, and renal function (22)), were hand-searched for additional reports. Two out of three authors (JW, SH, VA) reviewed the inclusion of each report based on title, then abstract, then full-text. Disagreements were resolved by joint full-text review with a third independent reviewer $(\mathrm{RH})$.

\section{Data extraction}

From each report the following information was extracted: design of cohort (consented participant cohort with research measures at baseline and follow-up, or electronic health record (EHR) cohort in which anonymised data collected as part of usual clinical care was used for baseline and follow-up measures), country, sample size (number of participants at baseline) and number of AF events over follow-up (based on the highest figure reported), age range, proportion of female participants, mean or median follow-up, methods of $\mathrm{AF}$ ascertainment, risk factor definition, statistical model, and risk factors used in adjustment. We extracted data on whether cardiovascular events, prevalent at baseline and incident during follow-up and preceding AF were accounted for. For each risk factor, we extracted adjusted relative risks (RR), and 95\% confidence intervals $[95 \% \mathrm{CI}]$. Where there were multiple RR reported within a publication, or across multiple publications from the same cohort, we selected the most adjusted estimate, modelled with the highest number of AF cases.

\section{Summary and visualisation of risk factor associations}

We summarised the overall results of the field of cohort epidemiology of AF by plotting the number of reports with inverse $(\mathrm{RR}<1.00)$, null or mixed ( $\mathrm{RR}=1.00$ or shows opposite associations among subpopulations), or direct relationship (RR $>1.00$ ) with $\mathrm{AF}$ incidence. We regarded the association as significant if the $95 \% \mathrm{CI}$ did not cross unity. Unless stated, RR are given as originally reported. For each factor, we then plotted the RR and $95 \%$ CI using R-3.2.0 (CALIBERdatamanage package, available at: caliberresearch.org). 


\section{Summary and visualisation of quality of reporting and analysis}

We summarised the quality of reporting by completeness of the items listed in the above data extraction section (items not reported (NR) are clearly indicated in tables and figures). We summarised the quality of analysis by assessment of the number (\%) of adjustment made for the 23 risk factors, and whether adjustment was made for six standard CVD risk factors (age, sex, smoking, blood pressure, lipids and diabetes mellitus), and for prevalent and incident CVD events. We visualised these as "Swiss cheese" plots (26).

\section{Results}

\section{Characteristics of included reports}

Out of 2777 publications, 73 were included (Suppl. Figure S1, Appendix p 4) with 84 reports on 32 cohorts from 10 countries and 20,420,175 participants (16, 27-98). As Table 2 (available online at www.thrombosis-online.com) shows, 28 (87.5\%) cohorts involved consented participants with 39,900 (6.9\%) events, and four cohorts (12.5\%) were EHR-based with 536,702 (93.1\%) events. AF events were ascertained from a research electrocardiogram (40 reports $(47.6 \%)$ ), diagnosis codes from medical records (60 reports $(71.4 \%)$ ), or using a combination of both methods (24 reports (28.6\%)). As Suppl. Table S1 (Appendix pp 5-7) shows, 17 reports $(20.2 \%)$ described using two out of four types of medical records (i.e. general practitioner, hospital care, prescriptions, or mortality records), but no report used three or all four types combined.

\section{Quality of reporting}

Age range was not reported in 30 reports $(35.7 \%)$, mean or median follow-up in 18 reports $(21.4 \%)$, and risk factor definition was not reported in nine reports (10.7\%). Information was consistently reported on country, sample size, female participants, and AF events.

\section{Quality of analysis}

Overall, 63 reports $(75.0 \%)$ lacked adjustment for all six standard CVD risk factors (Suppl. Table S2, Appendix pp 8-9). Age was adjusted for in 84 reports (100.0\%), sex in 80 reports (95.2\%), smoking in 49 reports $(58.3 \%)$, blood pressure in 63 reports $(75.0 \%)$, lipids in 32 reports $(38.1 \%)$, and diabetes mellitus in 59 reports $(70.2 \%)$. The total number of adjustment factors ranged from 2-14 factors, with a median of eight factors. There was lack of adjustment for prevalent CVD in 30 reports (35.7\%), and for incident CVD in 69 reports $(82.1 \%)$.
Table 1: 23 cardiovascular risk factors investigated for their associations with incident atrial fibrillation in populations based cohorts.

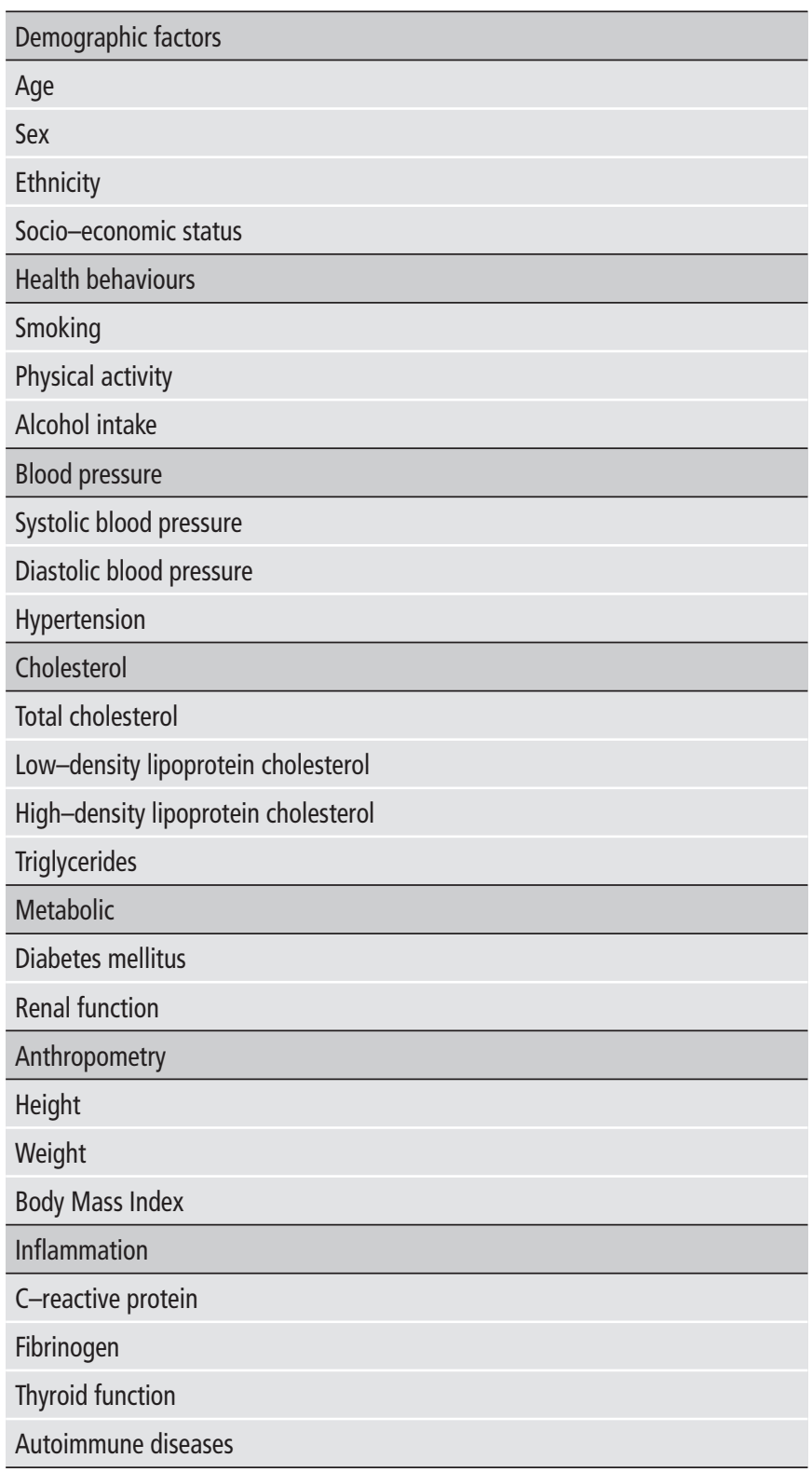

\section{Associations of 23 risk factors and incidence of $A F$}

A summary of the heterogeneity of associations of 23 risk factors and incidence of AF are visualised in $>$ Figure 1 , and for each factor separately in $>$ Figures 2-6 and Suppl. Figures S2-S19 (Appendix pp 12-29). There was no evidence of small study bias.

\section{Demographic factors}

For age, all 15 reports showed significant direct associations, but these were heterogeneous. RR [95\%CI] ranged from 1.02 [1.01-1.03] to $1.14[1.10-1.18]$ for every 1 -year, from 1.43 


\begin{tabular}{|c|c|c|c|c|c|c|}
\hline \multirow[b]{2}{*}{ Risk Factor } & \multirow[b]{2}{*}{$\begin{array}{l}\text { Total } \\
\text { reports }\end{array}$} & \multicolumn{2}{|c|}{ AF events } & \multirow{2}{*}{\multicolumn{2}{|c|}{ Direction of association }} & \multirow[b]{2}{*}{ References } \\
\hline & & $\begin{array}{l}\text { Consented } \\
\text { studies }\end{array}$ & $\begin{array}{l}\text { EHR } \\
\text { studies }\end{array}$ & & & \\
\hline Age & 15 & 16078 & 127258 & & $\bullet \bullet \bullet \bullet \bigcirc \bullet \bullet \bullet \bullet \bullet \bullet \bullet \bullet \bullet \bullet$ & $\begin{array}{l}88,98,35,55,94,50 \\
47,47,28,43,90,37 \\
70,32,67\end{array}$ \\
\hline Men & 11 & 6295 & 127258 & $\bullet \bullet \bullet$ & $\bullet \bullet \bullet \bullet \bullet \bullet \bullet$ & $\begin{array}{l}79,98,88,37,47,43 \\
94,4750,55,70\end{array}$ \\
\hline Non-White ethnicity & 5 & 10797 & 375318 & $\bullet \bullet \bullet \bullet \bullet$ & & $85,44,44,28,92$ \\
\hline Socio-economic & 6 & 13437 & 126217 & $\bullet \bullet 0$ & 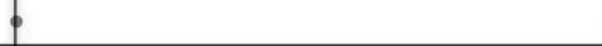 & $56,28,48,94,38,35$ \\
\hline Smoking & 13 & 18198 & 0 & $\bullet$ & 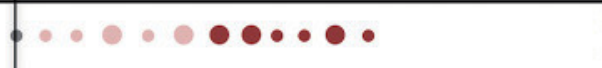 & $\begin{array}{l}35,47,83,88,56,70 \\
54,28,37,47,78,40,79\end{array}$ \\
\hline Physical activity & 11 & 22822 & 0 & $\bullet \bullet \bullet \bullet \bullet \bullet$ & $\circ$ & $\begin{array}{l}49,90,33,46,86,27 \\
59,6629,56,36\end{array}$ \\
\hline Alcohol intake & 10 & 18997 & 0 & $\bullet \bullet$ & $\phi \bullet \bullet \bullet \bullet \bullet$ & $\begin{array}{l}83,53,46,28,35,70 \\
79,1664,88\end{array}$ \\
\hline Systolic BP & 14 & 6981 & 0 & & $\bullet \bullet \bullet \bullet \bullet \bullet \bullet \bullet \bullet \bullet \bullet \bullet$ & $\begin{array}{l}79,35,55,83,47,50 \\
47,90,69,84,91,56 \\
65,46\end{array}$ \\
\hline Diastolic BP & 11 & 4796 & 0 & $\bullet \bullet \bullet \bullet \bullet \bullet \bullet$ & $\bullet \bullet \bullet$ & $\begin{array}{l}69,50,84,83,47,91 \\
55,47,65,90,46\end{array}$ \\
\hline Hypertension & 17 & 18128 & 1041 & - & $\bullet \bullet \bullet \bullet \bullet \bullet \bullet \bullet \bullet \bullet \bullet \bullet \bullet \bullet$ & $\begin{array}{l}88,55,50,37,79,35 \\
67,28,91,47,47,31 \\
70,40,56,98,87\end{array}$ \\
\hline Total cholesterol & 13 & 7129 & 0 & $\bullet \bullet \bullet \bullet \bullet \bullet \bullet \bullet \bullet \bullet \bullet$ & - & $\begin{array}{l}61,35,53,41,47 \\
67,83,3288,56 \\
47,71,71\end{array}$ \\
\hline LDL cholesterol & 7 & 3600 & 0 & $\bullet \bullet \bullet \bullet \bullet$ & - & $61,41,55,32,83,71,71$ \\
\hline HDL cholesterol & 10 & 5347 & 0 & $\bullet \bullet \bullet$ & $\phi \bullet \bullet \bullet$ & $\begin{array}{l}71,47,71,32,47,41 \\
47,8361,67\end{array}$ \\
\hline Triglycerides & 9 & 4525 & 0 & $\circ \circ$ & 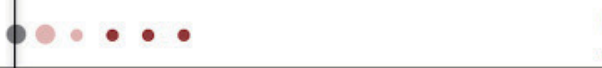 & $\begin{array}{l}61,83,32,47,41,47 \\
47,7171\end{array}$ \\
\hline Diabetes mellitus & 16 & 18670 & 116997 & - & $\circ \bullet \bullet \bullet \bullet \bullet \bullet \bullet \bullet \bullet \bullet \bullet \bullet$ & $\begin{array}{l}98,83,37,70,54,58 \\
95,50,47,47,67,88 \\
56,40,28,79\end{array}$ \\
\hline Renal function & 11 & 7403 & 127258 & $\bullet \bullet$ & $\bullet \bullet \bullet \circ \bullet \bullet$ & $\begin{array}{l}47,52,83,30,98,47 \\
47,6294,57,45\end{array}$ \\
\hline Height & 10 & 7181 & 0 & & $\bullet \bullet \bullet \bullet \bullet \bullet \bullet \bullet$ & $\begin{array}{l}53,56,70,67,47,34 \\
79,4789,46\end{array}$ \\
\hline Weight & 8 & 5016 & 0 & & $\bullet \bullet \bullet \bullet \bullet \bullet \bullet$ & $\begin{array}{l}47,47,47,47,34,79 \\
89,47\end{array}$ \\
\hline Body Mass Index & 19 & 22655 & 0 & & $\bullet \bullet \bullet \bullet \bullet \bullet \bullet \bullet \bullet \bullet \bullet \bullet \bullet \bullet \bullet \bullet \bullet \bullet \bullet$ & $\begin{array}{l}60,56,55,91,48,28,81 \\
90,67,70,76,89,34 \\
83,37,7931,39,88 \\
\end{array}$ \\
\hline C-reactive protein & 8 & 3545 & 0 & & $\bullet \bullet \bullet \bullet \bullet \bullet \bullet$ & $\begin{array}{l}83,75,73,68,63,75 \\
55,50\end{array}$ \\
\hline Fibrinogen & 6 & 3580 & 0 & $\circ \circ$ & $\bullet \bullet \bullet$ & $73,68,74,63,42,80$ \\
\hline Thyroid function & 8 & 1510 & 16710 & - & 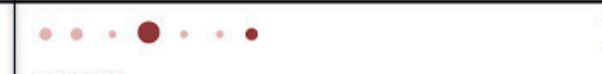 & $\begin{array}{l}82,51,77,82,96,82 \\
82,72\end{array}$ \\
\hline Autoimmunity & 3 & 0 & 286560 & & 00 & $97,93,94$ \\
\hline & & & & $\begin{array}{ll}\text { significant } \\
\text { inverse }\end{array} \quad \begin{array}{l}\text { non-sig. } \\
\text { inverse }\end{array}$ & $\begin{array}{l}\text { non-sig. } \\
\text { direct }\end{array}$ & \\
\hline & & & & - $<1000$ & $\geq 100000$ & \\
\hline
\end{tabular}

Figure 1: Associations of 23 risk factors and incidence of atrial fibrillation according to number of reports, number of events, and direction of association. AF - atrial fibrillation, BP - blood pressure, EHR - electronic health record, HDL - high-density lipoprotein, LDL - low-density lipoprotein, sig. - significant. Risk factor and reference group definitions are detailed in individual risk factors plots (Figures 2-6 and Suppl. Figures S2-S19 in Appendix, available online at www.thrombosis-online.com). Each dot represents one report, colour-coded to indicate the direction of association, and in order of most extreme inverse to most extreme direct point estimate. Dots are scaled by the number of AF events $(<100,100-<1000,1000-<10000$, $10000-<100000$, or $\geq 100000$ ). References correspond to each dot from left to right sequence. Associations are classified as inverse (relative risk (RR) $<1.00$ ), null or mixed ( $R R=1.00$ or show opposite associations among subpopulations), or direct ( $R R>1.00)$. Association were regarded as significant if the $95 \% \mathrm{Cl}$ did not cross unity. 


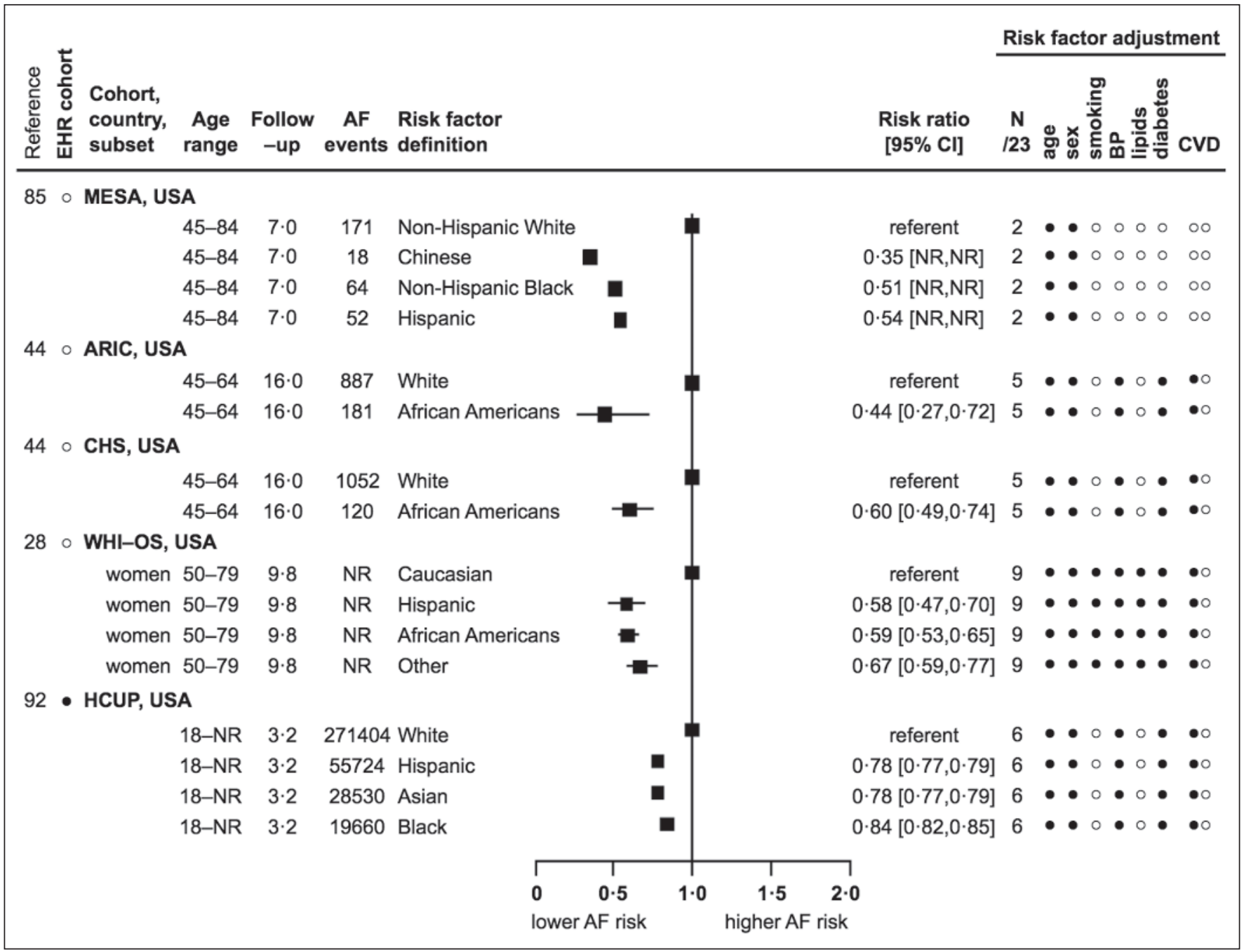

Figure 2: Association of ethnicity and incidence of AF: 5 reports from 1 country with 386,115 events. EHR - electronic health record, age range in years, follow-up in years (mean, median, or maximum), AF - atrial fibrillation, $\mathrm{Cl}$ - confidence interval, N/23 - number (of factors) out of 23, CVD cardiovascular disease, SD - standard deviation, NR - not reported, USA United States of America, $\bullet$ - yes, $0-$ no, -- - not applicable. Risk factor adjustment refers to whether adjustment was made for the 23 risk factors under review, 6 CVD risk factors, and prevalent and incident CVD events.
Example: ARIC adjusted for 5/23 risk factors, age, sex, blood pressure (i. e. any of systolic blood pressure, diastolic blood pressure, hypertension, or blood pressure lowering medication), and diabetes mellitus, but not smoking or lipids (i. e. any of total cholesterol, low-density lipoprotein cholesterol, high-density lipoprotein cholesterol, triglycerides, hyperlipidaemia, or lipid lowering medication), and prevalent, but not incident CVD events. For cohort abbreviations see Table 2 (available online at www.thrombosis-online.com).
[1.29-1.59] to 1.65 [1.57-1.74] for every 5-year, from 1.09 [1.09-1.09] to 2.35 [2.03-2.72] for every 10 -year, and from 1.36 $[1.27-1.45]$ to 4.34 [3.72-5.07] for every standard deviation (NR) year increase in age (Suppl. Figure S2 in Appendix) $(28,32,35,37$, $43,47,50,55,67,70,88,90,94,98$ ). For men (compared to women), one report showed a significant inverse association (0.70 [0.50-0.90]) (79), two reports were inverse but non-significant (from 0.95 to 0.96$)(88,98)$, and eight reports showed significant direct associations (from $1.45[1.29-1.63]$ to 1.90 [1.58-2.29]) (Suppl. Figure S3 in Appendix) (37, 43, 47, 50, 55, 70, 94). For African-American, Asian, Chinese, Hispanic and Non-Hispanic Black (compared to White) ethnicities, all five reports showed significant inverse associations (from 0.35 [NR-NR] to 0.84 [0.82-0.85]) (28, $44,85,92)$. Only one country reported estimates for the association of ethnicity and incidence of AF ( Figure 2). For socio-economic status, two reports showed significant inverse associations, three reports were inverse but non-significant, and one report showed a mixed association (see Appendix p 10 and Suppl. Figure S4 for further details).

\section{Health behaviours}

For current smoking, one report was inverse but non-significant (0.78) (35), one report showed a mixed association (47), five re- 


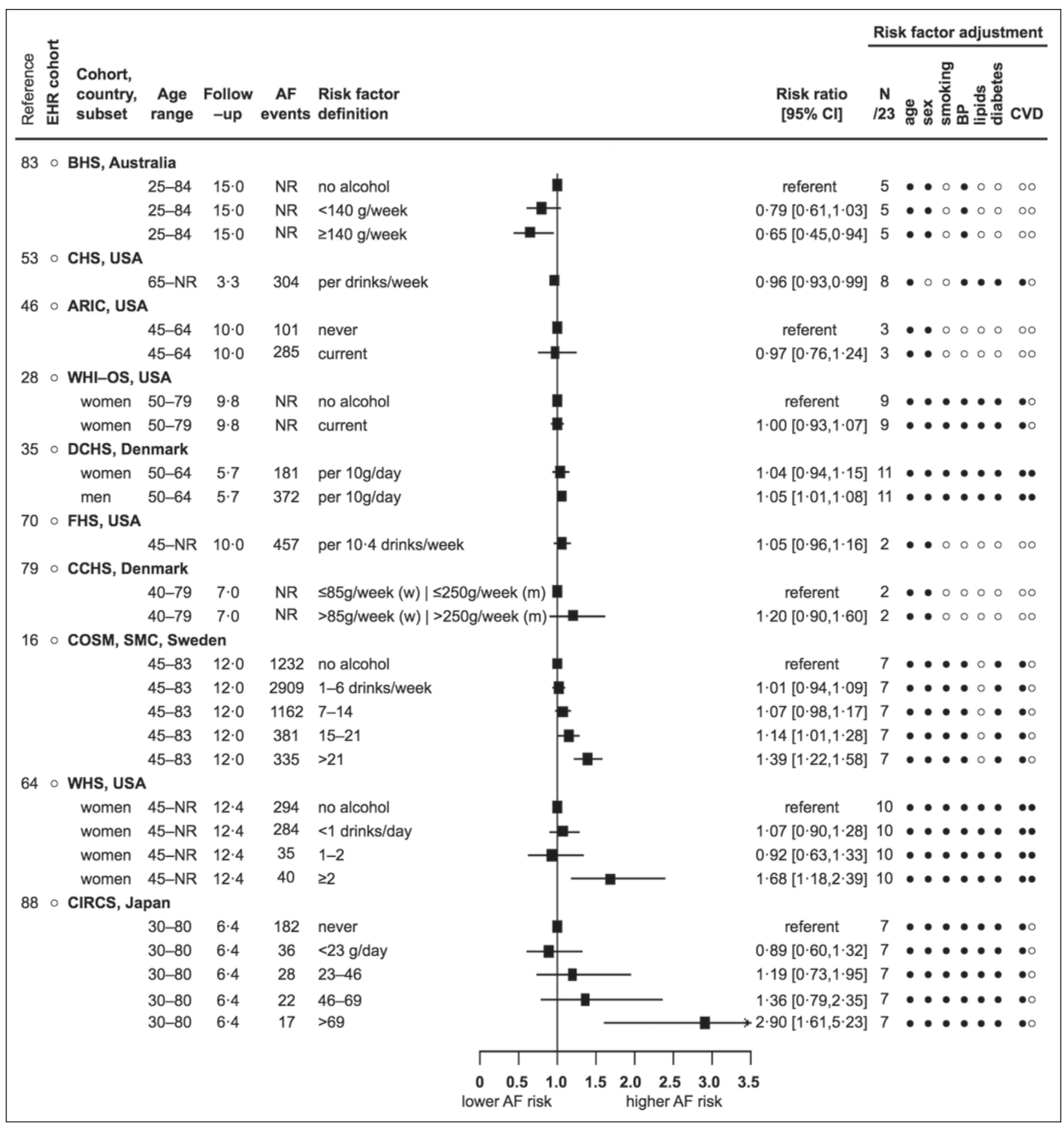

Figure 3: Association of alcohol intake and incidence of AF: 10 reports from 5 countries with 18,997 events. Legend see Figure 2 abbreviations, and $\mathrm{g}$ - grams, (w) - women, (m) - men.

ports were direct but non-significant (from 1.01 to 1.20$)(54,56$, $70,83,88$ ), and six reports showed significant direct associations (from 1.32 [1.19-1.46] to 2.00 [1.40-2.80]) (Suppl. Figure S5 in Appendix, available online at www.thrombosis-online.com) (28, $37,40,47,78,79)$. For physical activity, three reports showed significant inverse associations, four reports were inverse but non- significant, two reports showed null or mixed associations, and two reports were direct but non-significant (see Appendix p 10 and Suppl. Figure S6). For alcohol intake in drinks per day or week, in grams per day or week, or for current alcohol drinkers, two reports showed significant inverse associations (from 0.65 [0.45-0.94] to 0.96 [0.93-0.99]) $(53,83)$, one report was inverse 


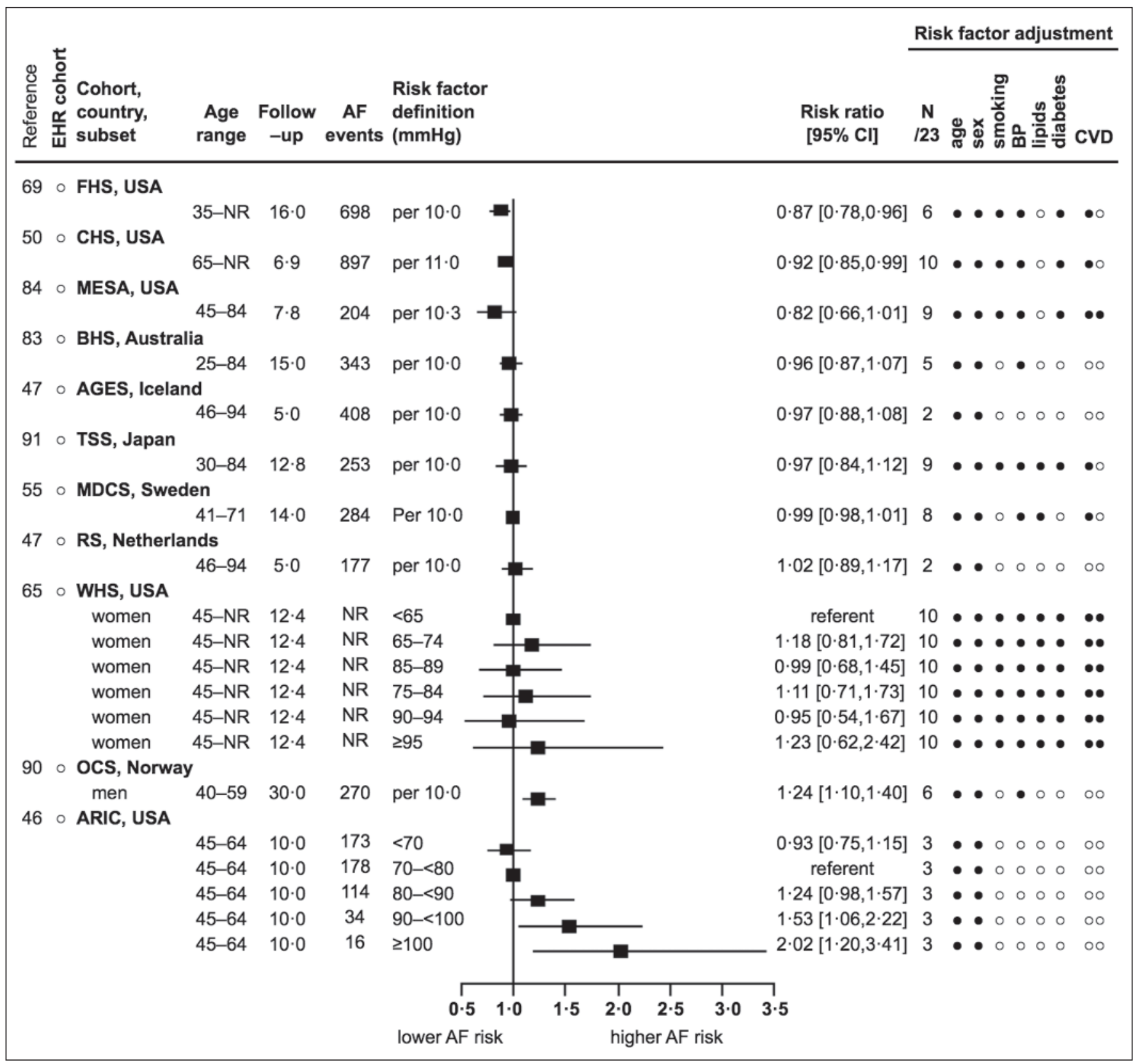

Figure 4: Association of diastolic blood pressure and incidence of AF: 11 reports from 7 countries with 4796 events. See Figure 2 abbreviations, and $\mathrm{mmHg}$ - millimetres of mercury. Risk factor adjustment for BP in this instance refers to whether systolic blood pressure, hypertension, or blood pressure lowering medication were adjusted for.

but non-significant (0.97) (46), one report showed a null association (28), three reports were direct but non-significant (from 1.04 to 1.20$)(35,70,79)$, and three reports showed significant direct associations (from 1.39 [1.22-1.58] to 2.90 [1.61-5.23]) $(16,64,88)$. All 10 alcohol reports defined alcohol intake differently, and as shown for the three direct alcohol associations, the increased risk of developing AF was only among the highest alcohol intake categories ( $\gg$ Figure 3 ).

\section{Blood pressure}

For every 10-22 mmHg increase in systolic blood pressure, or systolic blood pressure $\geq 160 \mathrm{mmHg}$, one report showed a null association (79), five reports were direct but non-significant (from 1.01 to 1.24$)(35,47,55,83,84)$, and eight reports showed significant direct associations (from $1.14[1.05-1.25]$ to $2.63[1.83-3.78]$ ) (Suppl. Figure S7 in Appendix) (46, 47, 50, 56, 65, 69, 90, 91). For every 10-11 mmHg increase in diastolic blood pressure, or diastolic blood pressure $\geq 95-100 \mathrm{mmHg}$, two reports showed signifi- 


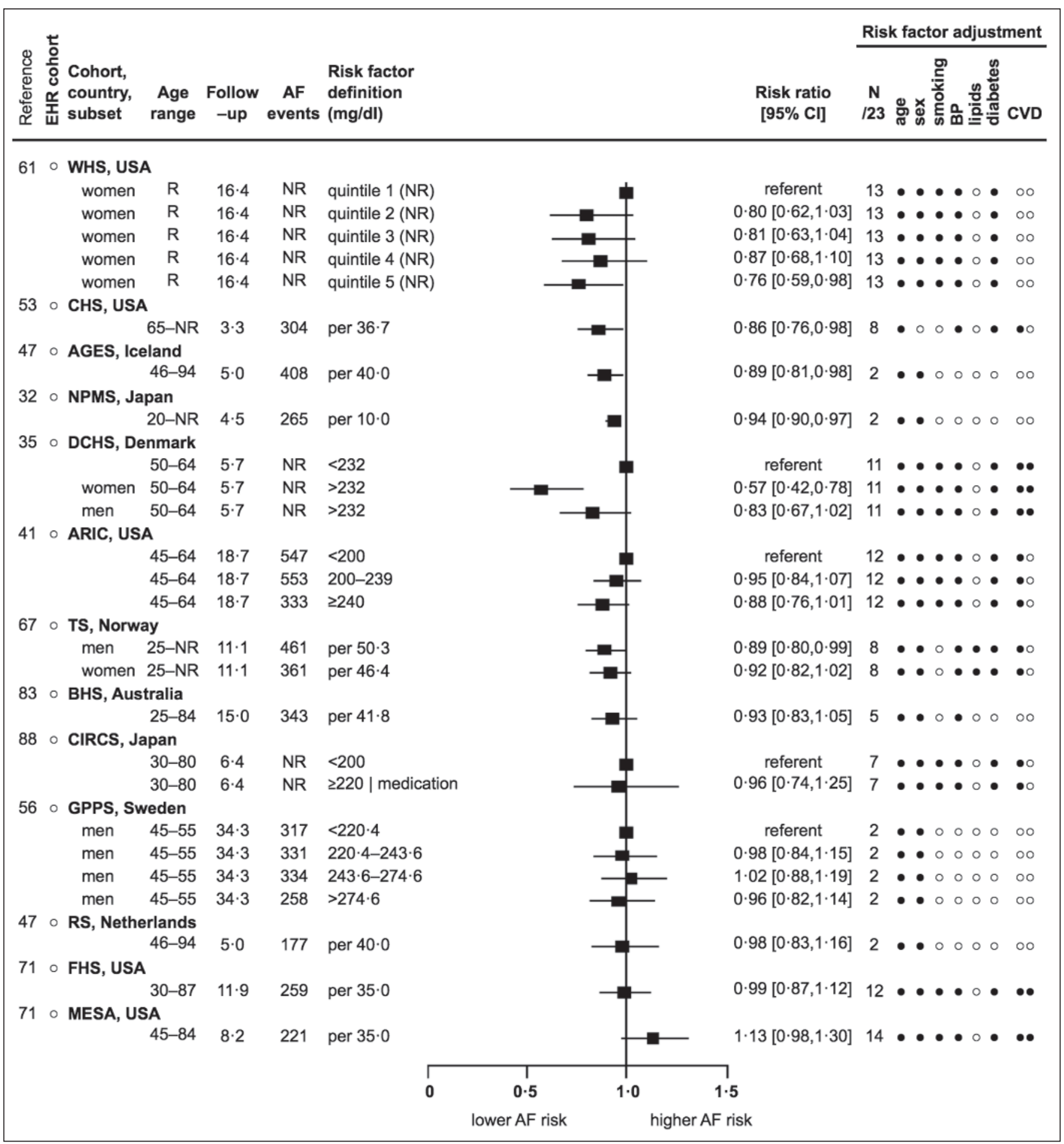

Figure 5: Association of total cholesterol and incidence of AF: 13 reports from 8 countries with 7129 events. See Figure 2 abbreviations, and $\mathrm{mg} / \mathrm{dl}$ - milligrams per decilitre, $\mathrm{mmol} / \mathrm{l}$ - millimoles per litre. Risk factor adjustment for lipids in this instance refers to whether low-density lipopro- tein cholesterol, high-density lipoprotein cholesterol, triglycerides, hyperlipidaemia, or lipid lowering medication were adjusted for. Total cholesterol reported as $\mathrm{mmol} / \mathrm{l}$ for CHS, GPPS, TS and BHS was converted to $\mathrm{mg} / \mathrm{dl}$ using the conversion $1 \mathrm{mmol} / \mathrm{l}=38.66976 \mathrm{mg} / \mathrm{dl}$. cant inverse associations (from 0.87 [0.78-0.96] to 0.92 [0.85-0.99]) $(50,69)$, five reports were inverse but non-significant (from 0.82 to 0.99$)(47,55,83,84,91)$, two reports were direct but non-significant (from 1.02 to 1.23$)(47,65)$, and two reports showed significant direct associations (from 1.24 [1.10-1.40] to $2.02[1.20-3.41])(46,90)$. No EHR cohorts reported estimates for the association of diastolic blood pressure and incidence of AF ( $>$ Figure 4). For hypertension, one report was inverse but non- 


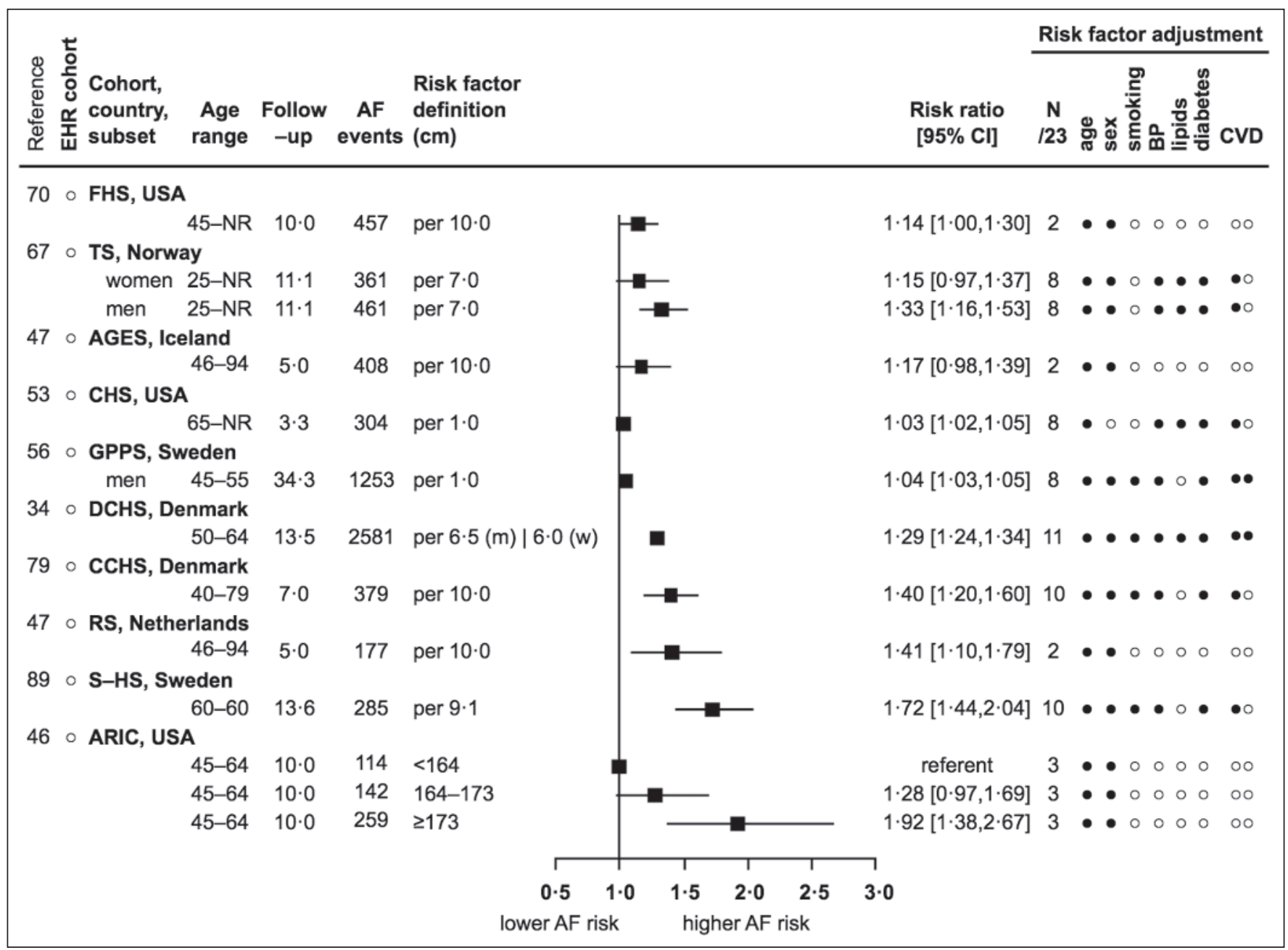

Figure 6: Association of height and incidence of AF: 10 reports from 6 countries with 7181 events. See Figure 2 abbreviations, and cm - centimetres, $(\mathrm{m})$ - men, $(\mathrm{w})$ - women.

significant (0.93) (88), three reports were direct but non-significant (from 1.21 to 1.37$)(35,55,79)$, and 13 reports showed significant direct associations (from $1.28[1.08-1.51]$ to $2.60[1.60-4.40]$ ) (Suppl. Figure S8 in Appendix) (28, 31, 37, 40, 47, 50, 56, 67, 70, 87, 91, 98).

\section{Lipid profile}

For every $10-50 \mathrm{mg} / \mathrm{dl}$ increase in total cholesterol, or total cholesterol $\geq 220-280 \mathrm{mg} / \mathrm{dl}$, four reports showed significant inverse associations (from 0.76 [0.59-0.98] to 0.94 [0.90-0.97]) $(32,47,53$, 61), eight reports were inverse but non-significant (from 0.57 to $0.99)(35,41,47,56,67,71,83,88)$, and one report was direct but non-significant (1.13) (71). Both inverse and direct associations were shown in the three total cholesterol reports that adjusted for prevalent and incident CVD events ( $\$$ Figure 5). For every 10-40 $\mathrm{mg} / \mathrm{dl}$ increase in low-density lipoprotein cholesterol, or low-density lipoprotein cholesterol $\geq 150 \mathrm{mg} / \mathrm{dl}$, two reports showed significant inverse associations (from $0.72[0.56-0.92]$ to 0.92
$[0.88-0.96])(32,61)$, four reports were inverse but non-significant (from 0.85 to 0.95$)(41,55,71,83)$, and one report was direct but non-significant (1.15) (Suppl. Figure S9 in Appendix) (71). For every $15 \mathrm{mg} / \mathrm{dl}$ increase in high-density lipoprotein cholesterol, or high-density lipoprotein cholesterol $\geq 60 \mathrm{mg} / \mathrm{dl}$, five reports were inverse but non-significant (from 0.85 to 0.98$)(32,47,71)$, two reports showed null or mixed associations $(41,47)$, two reports were direct but non-significant (from 1.01 to 1.07$)(61,83)$, and one report showed a significant direct association (1.16 [1.04-1.28]) (Suppl. Figure 10 in Appendix) (67). For triglycerides, three reports were inverse but non-significant, one report showed a mixed association, two reports were direct but non-significant, and three reports showed significant direct associations (see Appendix p 10 and Suppl. Figure S11).

\section{Diabetes mellitus, renal function}

For diabetes mellitus (type unspecified), two reports were inverse but non-significant (from 0.86 to 0.98$)(83,98)$, eight reports were 
direct but non-significant (from 1.02 to 1.49$)(37,47,54,56,58$, $67,70)$, and six reports showed significant direct associations (from 1.17 [1.16-1.19] to 1.80 [1.30-2.60]) (Suppl. Figure S12 in Appendix) (28, 40, 50, 79, 88, 95). For renal function, three reports were inverse but non-significant, five reports were direct but nonsignificant, and three reports showed significant direct associations (see Appendix p 11 and Suppl. Figure S13).

\section{Anthropometric factors}

For every 1-10 cm increase in height, or height $\geq 173 \mathrm{~cm}$, three reports were direct but non-significant (from 1.14 to 1.17$)(47,67$, 70 ), and seven reports showed significant direct associations (from 1.03 [1.02-1.05] to 1.92 [1.38-2.67]) $(34,46,47,53,56,79,89)$ ( Figure 6). For weight, all eight reports showed significant direct associations (see Appendix p 11 and Suppl. Figure S14). For every $1-10 \mathrm{~kg} / \mathrm{m}^{2}$ increase in body mass index (BMI), or BMI $\geq 25-30$ $\mathrm{kg} / \mathrm{m}^{2}$, all 19 reports showed significant direct associations (from 1.04 [1.02-1.05] to 2.24 [1.41-3.58]) (Suppl. Figure S15 in Appendix) $(28,31,34,37,39,48,55,56,60,67,70,76,79,81,83,88-91)$.

\section{Inflammatory biomarkers}

For C-reactive protein, four reports were direct but non-significant, and four reports showed significant direct associations (see Appendix p 11 and Suppl. Figure S16). For fibrinogen, two reports were inverse but non-significant, one report was direct but nonsignificant, and three reports showed significant direct associations (see Appendix p 11 and Suppl. Figure S17).

\section{Thyroid function, autoimmune disease}

For every $1.0 \mathrm{mU} / \mathrm{l}$ decrease in thyroid stimulating hormone, or thyroid stimulating hormone $<0.10-0.45 \mathrm{mU} / \mathrm{l}$, one report was inverse but non-significant $(0.34)$ (82), five reports were direct but non-significant (from 1.06 to 2.85$)(51,77,82)$, and two reports showed significant direct associations (from 1.41 [1.25-1.59] to 3.10 [1.70-5.50]) (Suppl. Figure S18 in Appendix) $(72,96)$. For autoimmune diseases, all three reports showed significant direct associations (see Appendix p 11 and Suppl. Figure S19).

\section{Discussion}

To our knowledge this is the first example of a field synopsis evaluating associations across multiple risk factors and disease incidence. We systematically evaluated 84 reports from 32 independent cohorts for the impact of 23 cardiovascular risk factors on incidence of AF. Unlike previous overviews of AF risk factors (10, 99), we focussed exclusively on primary prevention among populations initially free from diagnosed CVD or general populations in which baseline levels of CVD reflected prevalence in the general population. We found some evidence that ethnicity, height, diastolic blood pressure and serum cholesterol, are associated with AF incidence in opposite directions to their known associations with
CHD and stroke. Furthermore we found only modest evidence for the widely held clinical opinion that excess alcohol is associated with risk of AF. Taken together our findings suggest that primary prevention strategies for AF may require some different elements from the current approaches used for other CVDs.

\section{Concordant associations}

For some risk factors - hypertension, and higher BMI - there were consistent, direct associations with incident $\mathrm{AF}$, as there are for $\mathrm{CHD}$. This could reflect a causal link with AF, or that the risk factor causes CHD, which in turn causes AF. Surprisingly, we found that only three (out of 14) reports investigating the association between systolic blood pressure and incident AF accounted for both prevalent and intercurrent incident cardiovascular events, and only one of which reported a significant direct association. Several post-hoc analyses of trials have suggested a possible benefit of ACE/ARB-inhibitors (100), and other blood-pressure lowering medications (101), for prevention of AF. However, we demonstrate that across all 23 risk factors, the available observational evidence does not fully consider a mechanism or confounding of reported associations by intercurrent CHD.

Current clinical guidelines include alcohol in a list of potentially "reversible" causes of AF, but acknowledge that there is no evidence to suggest addressing any of these is effective in preventing AF (9). We found a small number of reports (3 out of 10) suggesting a direct association between alcohol intake and AF incidence. This is in contrast to three existing alcohol reviews (Samokhvalov et al. (14), Kodama et al. (15) and Larsson et al. (16)), which have reported dose-response relationships. There are several possible explanations as to why our findings differ. Unlike the previous alcohol reviews, ours considers i) only prospective studies (Samokhvalov et al. and Kodama et al. included retrospective studies; similarly Larsson et al. focused on prospective studies), ii) only general population cohorts (Larsson et al. included one cohort with preexisting CVD), iii) only incident AF events (Kodama et al. included studies on AF recurrence), iv) only estimates from Cox or Poisson regression (Samokhvalov et al., Kodama et al., and Larsson et al. all included estimates from logistic regression), v) only the most adjusted alcohol estimate per cohort (Samokhvalov et al. included the study with the most comprehensive alcohol data, while Larsson et al. did not report an approach to selecting from multiple estimates per cohort), and lastly vi) our more recent review and more inclusive field synopsis method includes eight reports that have not been included in the previous reviews $(28,35$, $46,53,70,79,83,88)$. Based on the three direct alcohol associations we identified, the increased risk of developing AF was confined to the highest alcohol intake levels, as opposed to there being a J-shaped or dose-response relationship. Overall, our findings indicate that at present, there is limited consistent evidence on which recommended alcohol intake levels for primary prevention of $\mathrm{AF}$ could be based. 


\section{Discordant associations}

We found some evidence that white ethnicity, taller height, lower total cholesterol and lower diastolic blood pressure might confer a higher risk of incident $\mathrm{AF}$, which is in the opposite direction to their known associations with incident CHD (12). Our findings regarding cholesterol suggest that reducing cholesterol may not be relevant for the primary prevention of $\mathrm{AF}$, and are in line with an existing meta-analysis of trial evidence, which did not support the role of statins for prevention of AF in participants with underlying CVD (102). Previously, it been demonstrated that blood pressure has markedly different associations with the incidence of 12 individual cardiovascular diseases (not including AF) (103). We now provide some, albeit mixed, evidence that this may also be the case for AF. The direct and inverse associations shown for systolic and diastolic blood pressure respectively, may indicate high pulse pressure, which is a marker of arterial stiffness and is more prevalent in older populations (104). Two earlier studies found an association between pulse pressure and incidence of $\operatorname{AF}(69,84)$; however, pulse pressure was not considered in this review as its clinical utility is not well defined (105).

\section{Clinical implications}

The observational evidence summarised here suggests that programmes for AF primary prevention may need to differ slightly from those which have guided clinicians and public health practitioners in the primary prevention of other CVDs. Existing management strategies to tackle obesity, smoking, alcohol and hypertension may have a role but the current evidence is insufficient to design AF specific interventions. The risk factors included in available prediction tools for 5- or 10-year risk of incident AF are supported by our systematic review, and these tools should be used more frequently in clinical practice $(47,70)$. Such risk prediction tools could identify high-risk individuals for inclusion in primary prevention trials in AF, where there is the largest knowledge gap.

\section{Overall characteristics of the field}

Overall, we found a relatively "young" field, which has been rapidly expanding over the last five years (see Suppl. Figure S20, Appendix p 30). Although we included 32 cohorts of 20 million participants and 600,000 AF events, we found a limited number of reports (between 3 and 19) per risk factor. Although we identified some efforts at pooling studies (e.g. the CHARGE-AF consortium of 5 cohorts, 3 countries, and 1771 AF events (47)), the amount of evidence available is markedly smaller than the scale of cohort evidence available on risk factors for CHD or stroke incidence (e.g. The Emerging Risk Factor Collaboration consists of over 100 cohorts (106)). Next, we found that the AF field is beginning to span both consented population and electronic health record studies, with all seven EHR reports published in 2011-2015. In the era of "big data" research, EHRs offer the potential for studying associations at much larger scale, at population-level, in comparison with other risk factors, and across a wide range of diseases (107).

\section{What is known about this topic?}

- Atrial fibrillation is the world's most common heart rhythm disorder, and leading cause of fatal and disabling strokes, yet current clinical practice guidelines offer no recommendations for primary prevention in individuals without pre-existing cardiovascular disease.

- Established primary prevention strategies of other cardiovascular diseases (e.g. coronary heart disease and stroke), are based on understanding of risk factors, but whether the same risk factors are associated with incident atrial fibrillation remains unclear.

- There is a lack of systematic reviews and field synopses of risk factors for atrial fibrillation among general populations and populations initially free from diagnosed CVD.

\section{What does this paper add?}

- A systematic evaluation of evidence from 28 consented and four electronic health record cohorts confirms the importance of hypertension and obesity, but suggests important differences in the risk factors for incident atrial fibrillation as compared with other cardiovascular diseases.

- Non-white ethnicity, shorter height, higher cholesterol and higher diastolic blood pressure all showed some evidence of being associated with lower risk of incident AF. This contrasts with the known associations of these risk factors in the opposite direction with coronary heart disease.

- The evidence for the widely held clinical opinion that alcohol use is associated with incident $A F$ in the primary preventative setting was modest.

- These findings provide a systematic basis on which to direct research into the primary prevention of AF.

None of the EHR cohorts analysed continuous measures of blood pressure, lipids, BMI, or renal function. Linking data from consented population and EHR sources therefore represents an important research opportunity to investigate risk factors for AF at depth and at scale. Finally, we found considerable heterogeneity in study design and reporting, and a lack of consistent approach to adjustment for other risk factors (visualised as a "Swiss cheese"). Field synopses allow for differences in study designs, however in order to further inform primary preventive programmes and estimate the precision effect of each risk factor in meta-analyses; there is a need for large-scale strategic co-ordination of the field of AF prevention research.

\section{Strengths and limitations}

The principle strength of our study - evaluation across a comprehensive range of risk factors - is also the principle weakness. In order to evaluate the breadth of the field there is a necessary restriction in the depth of analysis of any one risk factor, or relations between them. As we only searched the PubMed database, it is possible that we may have missed relevant studies. We conducted a 


\section{Supplementary Material (Appendix) is available online at www.thrombosis-online.com.}

sensitivity analysis for the year 2013, and found no further eligible studies in EMBASE, which is consistent with other reports showing limited additional value of searching biomedical databases beyond PubMed $(108,109)$. There are of course other publications in support of searching multiple databases to identify further studies $(110,111)$. However, as we did not perform meta-analysis, we have not introduced any computational bias in to the present work and therefore consider our results and conclusions unlikely to change. Field synopses provide a systematic foundation, unbiased by a particular interest in one or more risk factors (112), for hypothesis generation and further research. One example of this would be to evaluate the extent to which the findings in relation to ethnicity, height and lipids (113) might be inter-related.

\section{Conclusions}

A systematic evaluation of the available evidence suggests similarities as well as important differences in the risk factors for AF as compared with other cardiovascular diseases. This has implications for the primary prevention of AF.

\section{Author contributions}

VA analysed, interpreted and visualised the data, and drafted the report. $\mathrm{HH}$ conceived the original research idea, and led the project as principal investigator. JW, RH, SH, VA conducted the literature search and selection of reports. JPC, PP, KIM contributed to the study methodology. $\mathrm{AB}$ contributed to the writing of the report. $\mathrm{AB}, \mathrm{RH}, \mathrm{RS}, \mathrm{SH}$ contributed to the clinical interpretation the data. AB, HH, JPC, JW, KIM, PP, RH, RS, SH, VA critically appraised and commented on interim drafts of the report, and approved the final version.

\section{Conflicts of interest}

None declared.

\section{References}

1. Chugh SS, et al. Worldwide epidemiology of atrial fibrillation: a Global Burden of Disease 2010 Study. Circulation 2014; 129: 837-847.

2. Marini C, et al. Contribution of atrial fibrillation to incidence and outcome of ischemic stroke: results from a population-based study. Stroke 2005; 36: 1115-1119.

3. Benjamin EJ, et al. Impact of atrial fibrillation on the risk of death: the Framingham Heart Study. Circulation 1998; 98: 946-952.

4. Blomstrom Lundqvist C, et al. What are the costs of atrial fibrillation? Europace 2011; 13 (Suppl 2): ii9-12.

5. Miyasaka Y, et al. Secular trends in incidence of atrial fibrillation in Olmsted County, Minnesota, 1980 to 2000, and implications on the projections for future prevalence. Circulation 2006; 114: 119-125.

6. Krijthe BP, et al. Projections on the number of individuals with atrial fibrillation in the European Union, from 2000 to 2060. Eur Heart J 2013; 34: 2746-2751.

7. Savelieva I, et al. Upstream therapies for management of atrial fibrillation: review of clinical evidence and implications for European Society of Cardiology guidelines. Part I: primary prevention. Europace 2011; 13: 308-328.
8. Moran PS, et al. Effectiveness of systematic screening for the detection of atrial fibrillation. Cochrane Database System Rev 2013; 4: Cd009586.

9. January CT, et al. 2014 AHA/ACC/HRS guideline for the management of patients with atrial fibrillation: executive summary: a report of the American College of Cardiology/American Heart Association Task Force on practice guidelines and the Heart Rhythm Society. Circulation 2014; 130: 2071-2104.

10. Kirchhof P, et al. 2016 ESC Guidelines for the management of atrial fibrillation developed in collaboration with EACTS: The Task Force for the management of atrial fibrillation of the European Society of Cardiology (ESC)Developed with the special contribution of the European Heart Rhythm Association (EHRA) of the ESCEndorsed by the European Stroke Organisation (ESO). Eur Heart J 2016; Epub ahead of print.

11. Jones $\mathrm{C}$, et al. The management of atrial fibrillation: summary of updated NICE guidance. Br Med J 2014; 348: g3655.

12. Perk J, et al. European Guidelines on cardiovascular disease prevention in clinical practice (version 2012). The Fifth Joint Task Force of the European Society of Cardiology and Other Societies on Cardiovascular Disease Prevention in Clinical Practice (constituted by representatives of nine societies and by invited experts). Eur Heart J 2012; 33: 1635-1701.

13. Goldstein LB, et al. Guidelines for the primary prevention of stroke: a guideline for healthcare professionals from the American Heart Association/American Stroke Association. Stroke 2011; 42: 517-584.

14. Samokhvalov AV, et al. Alcohol consumption as a risk factor for atrial fibrillation: a systematic review and meta-analysis. Eur J Cardiovasc Prevent Rehabil 2010; 17: 706-712.

15. Kodama S, et al. Alcohol consumption and risk of atrial fibrillation: a metaanalysis. J Am Coll Cardiol 2011; 57: 427-436.

16. Larsson SC, et al. Alcohol consumption and risk of atrial fibrillation: a prospective study and dose-response meta-analysis. J Am Coll Cardiol 2014; 64: 281-289.

17. Wu N, et al. Association of inflammatory factors with occurrence and recurrence of atrial fibrillation: a meta-analysis. Internat J Cardiol 2013; 169: 62-72.

18. Huxley RR, et al. Meta-analysis of cohort and case-control studies of type 2 diabetes mellitus and risk of atrial fibrillation. Am J Cardiol 2011; 108: 56-62.

19. Wanahita N, et al. Atrial fibrillation and obesity--results of a meta-analysis. Am Heart J 2008; 155: 310-315.

20. Ofman P, et al. Regular physical activity and risk of atrial fibrillation: a systematic review and meta-analysis. Circulation Arrhythm Electrophysiol 2013; 6: 252-256.

21. Kwok CS, et al. Physical activity and incidence of atrial fibrillation: a systematic review and meta-analysis. Internat J Cardiol 2014; 177: 467-476.

22. Zimmerman D, et al. Systematic review and meta-analysis of incidence, prevalence and outcomes of atrial fibrillation in patients on dialysis. Nephrol Dial Transplant 2012; 27: 3816-3822.

23. Ioannidis JP, et al. Assessment of cumulative evidence on genetic associations: interim guidelines. Internat J Epidemiol 2008; 37: 120-132.

24. Kuper $\mathrm{H}$, et al. Evaluating the causal relevance of diverse risk markers: horizontal systematic review. Br Med J 2009; 339: b4265.

25. Moher D, et al. Preferred reporting items for systematic reviews and meta-analyses: the PRISMA statement. Br Med J 2009; 339: b2535.

26. Hemingway $\mathrm{H}$, et al. Evaluating the quality of research into a single prognostic biomarker: a systematic review and meta-analysis of 83 studies of C-reactive protein in stable coronary artery disease. PLoS Med 2010; 7: e1000286.

27. Azarbal F, et al. Obesity, physical activity, and their interaction in incident atrial fibrillation in postmenopausal women. J Am Heart Assoc 2014; 3: pii: e001127.

28. Perez MV, et al. Risk factors for atrial fibrillation and their population burden in postmenopausal women: the Women's Health Initiative Observational Study. Heart 2013; 99: 1173-1178.

29. Drca N, et al. Atrial fibrillation is associated with different levels of physical activity levels at different ages in men. Heart 2014; 100: 1037-1042.

30. Watanabe $\mathrm{H}$, et al. Close bidirectional relationship between chronic kidney disease and atrial fibrillation: the Niigata preventive medicine study. Am Heart J 2009; 158: 629-636.

31. Watanabe $\mathrm{H}$, et al. Metabolic syndrome and risk of development of atrial fibrillation: the Niigata preventive medicine study. Circulation 2008; 117: 1255-1260.

32. Watanabe $\mathrm{H}$, et al. Association between lipid profile and risk of atrial fibrillation. Circulation J 2011; 75: 2767-2774.

33. Drca N, et al. Physical activity is associated with a reduced risk of atrial fibrillation in middle-aged and elderly women. Heart 2015; 101: 1627-1630. 
34. Frost L, et al. Body fat, body fat distribution, lean body mass and atrial fibrillation and flutter. A Danish cohort study. Obesity 2014; 22: 1546-1552.

35. Frost L, et al. Overweight and obesity as risk factors for atrial fibrillation or flutter: the Danish Diet, Cancer, and Health Study. Am J Med 2005; 118: 489-495.

36. Frost L, et al. Work related physical activity and risk of a hospital discharge diagnosis of atrial fibrillation or flutter: the Danish Diet, Cancer, and Health Study. Occupat Environment Med 2005; 62: 49-53.

37. Fedorowski A, et al. Orthostatic hypotension and long-term incidence of atrial fibrillation: the Malmo Preventive Project. J Intern Med 2010; 268: 383-389.

38. Misialek JR, et al. Socioeconomic status and the incidence of atrial fibrillation in whites and blacks: the Atherosclerosis Risk in Communities (ARIC) study. J Am Heart Assoc 2014; 3: pii: e001159.

39. Huxley RR, et al. Physical activity, obesity, weight change, and risk of atrial fibrillation: the Atherosclerosis Risk in Communities study. Circulation Arrhyth Electrophysiol 2014; 7: 620-625.

40. Huxley RR, et al. Absolute and attributable risks of atrial fibrillation in relation to optimal and borderline risk factors: the Atherosclerosis Risk in Communities (ARIC) study. Circulation 2011; 123: 1501-1508.

41. Lopez FL, et al. Blood lipid levels, lipid-lowering medications, and the incidence of atrial fibrillation: the atherosclerosis risk in communities study. Circulation Arrhyth Electrophysiol 2012; 5: 155-162.

42. Alonso A, et al. Hemostatic markers are associated with the risk and prognosis of atrial fibrillation: the ARIC study. Internat J Cardiol 2012; 155: 217-222.

43. Alonso A, et al. Incidence of atrial fibrillation in whites and African-Americans: the Atherosclerosis Risk in Communities (ARIC) study. Am Heart J 2009; 158: 111-117.

44. Marcus GM, et al. European ancestry as a risk factor for atrial fibrillation in African Americans. Circulation 2010; 122: 2009-2015.

45. Alonso A, et al. Chronic kidney disease is associated with the incidence of atrial fibrillation: the Atherosclerosis Risk in Communities (ARIC) study. Circulation 2011; 123: 2946-2953.

46. Chamberlain AM, et al. A clinical risk score for atrial fibrillation in a biracial prospective cohort (from the Atherosclerosis Risk in Communities [ARIC] study). Am J Cardiol 2011; 107: 85-91.

47. Alonso A, et al. Simple risk model predicts incidence of atrial fibrillation in a racially and geographically diverse population: the CHARGE-AF consortium. J Am Heart Assoc 2013; 2: e000102.

48. Jensen PN, et al. Racial differences in the incidence of and risk factors for atrial fibrillation in older adults: the cardiovascular health study. J Am Geriatr Soc 2013; 61: 276-280.

49. Mozaffarian D, et al. Physical activity and incidence of atrial fibrillation in older adults: the cardiovascular health study. Circulation 2008; 118: 800-807.

50. Aviles RJ, et al. Inflammation as a risk factor for atrial fibrillation. Circulation 2003; 108: 3006-3010.

51. Cappola AR, et al. Thyroid function in the euthyroid range and adverse outcomes in older adults. J Clin Endocrinol Metabol 2015; 100: 1088-1096.

52. Deo R, et al. Impaired kidney function and atrial fibrillation in elderly subjects. J Cardiac Fail 2010; 16: 55-60.

53. Psaty BM, et al. Incidence of and risk factors for atrial fibrillation in older adults. Circulation 1997; 96: 2455-2461.

54. Smith JG, et al. Atrial fibrillation in the Malmo Diet and Cancer study: a study of occurrence, risk factors and diagnostic validity. Eur J Epidemiol 2010; 25: 95-102.

55. Smith JG, et al. Assessment of conventional cardiovascular risk factors and multiple biomarkers for the prediction of incident heart failure and atrial fibrillation. J Am Coll Cardiol 2010; 56: 1712-1719.

56. Rosengren A, et al. Big men and atrial fibrillation: effects of body size and weight gain on risk of atrial fibrillation in men. Eur Heart J 2009; 30: 1113-1120.

57. Xu D, et al. Anemia and reduced kidney function as risk factors for new onset of atrial fibrillation (from the Ibaraki prefectural health study). Am J Cardiol 2015; 115: 328-333.

58. Schoen T, et al. Type 2 diabetes mellitus and risk of incident atrial fibrillation in women. J Am Coll Cardiol 2012; 60: 1421-1428.

59. Everett BM, et al. Physical activity and the risk of incident atrial fibrillation in women. Circulation Cardiovasc Qual Outcom 2011; 4: 321-327.

60. Tedrow UB, et al. The long- and short-term impact of elevated body mass index on the risk of new atrial fibrillation the WHS (women's health study). J Am Coll Cardiol 2010; 55: 2319-2327.
61. Mora S, et al. Paradoxical association of lipoprotein measures with incident atrial fibrillation. Circulation Arrhythm Electrophysiol 2014; 7: 612-619.

62. Sandhu RK, et al. Relation of renal function to risk for incident atrial fibrillation in women. Am J Cardiol 2012; 109: 538-542.

63. Conen D, et al. A multimarker approach to assess the influence of inflammation on the incidence of atrial fibrillation in women. Eur Heart J 2010; 31: $1730-1736$.

64. Conen D, et al. Alcohol consumption and risk of incident atrial fibrillation in women. J Am Med Assoc 2008; 300: 2489-2496.

65. Conen D, et al. Influence of systolic and diastolic blood pressure on the risk of incident atrial fibrillation in women. Circulation 2009; 119: 2146-2152.

66. Thelle DS, et al. Resting heart rate and physical activity as risk factors for lone atrial fibrillation: a prospective study of 309,540 men and women. Heart 2013; 99: 1755-1760.

67. Nyrnes A, et al. Palpitations are predictive of future atrial fibrillation. An 11-year follow-up of 22,815 men and women: the Tromso Study. Eur J Prevent Cardiol 2013; 20: 729-736.

68. Nyrnes A, et al. Inflammatory biomarkers as risk factors for future atrial fibrillation. An eleven-year follow-up of 6315 men and women: the Tromso study. Gender Med 2012; 9: 536-547.e2.

69. Mitchell GF, et al. Pulse pressure and risk of new-onset atrial fibrillation. J Am Med Assoc 2007; 297: 709-715.

70. Schnabel RB, et al. Development of a risk score for atrial fibrillation (Framingham Heart Study): a community-based cohort study. Lancet 2009; 373: 739-745.

71. Alonso A, et al. Blood lipids and the incidence of atrial fibrillation: the MultiEthnic Study of Atherosclerosis and the Framingham Heart Study. J Am Heart Assoc 2014; 3: e001211.

72. Sawin CT, et al. Low serum thyrotropin concentrations as a risk factor for atrial fibrillation in older persons. N Engl J Med 1994; 331: 1249-1252.

73. Schnabel RB, et al. Relation of multiple inflammatory biomarkers to incident atrial fibrillation. Am J Cardiol 2009; 104: 92-96.

74. Adamsson Eryd S, et al. Inflammation-sensitive proteins and risk of atrial fibrillation: a population-based cohort study. Eur J Epidemiol 2011; 26: 449-455.

75. Sinner MF, et al. B-type natriuretic peptide and C-reactive protein in the prediction of atrial fibrillation risk: the CHARGE-AF Consortium of communitybased cohort studies. Europace 2014; 16: 1426-1433.

76. Schnabel RB, Aspelund T, Li G, et al. Validation of an atrial fibrillation risk algorithm in whites and African Americans. Arch Intern Med 2010; 170: 1909-1917.

77. Chaker L, et al. Normal Thyroid Function and the Risk of Atrial Fibrillation: the Rotterdam Study. J Clin Endocrinol Metabol 2015; 100: 3718-3724.

78. Heeringa J, et al. Cigarette smoking and risk of atrial fibrillation: the Rotterdam Study. Am Heart J 2008; 156: 1163-1169.

79. Friberg J, et al. Rising rates of hospital admissions for atrial fibrillation. Epidemiology 2003; 14: 666-672.

80. Mukamal KJ, et al. Fibrinogen and albumin levels and risk of atrial fibrillation in men and women (the Copenhagen City Heart Study). Am J Cardiol 2006; 98 : 75-81.

81. Aronis KN, et al. Associations of obesity and body fat distribution with incident atrial fibrillation in the biracial health aging and body composition cohort of older adults. Am Heart J 2015; 170: 498-505.e2.

82. Collet TH, et al. Subclinical hyperthyroidism and the risk of coronary heart disease and mortality. Arch Intern Med 2012; 172: 799-809.

83. Knuiman M, et al. A cohort study examination of established and emerging risk factors for atrial fibrillation: the Busselton Health Study. Eur J Epidemiol 2014; 29: 181-190.

84. Roetker NS, et al. Relation of systolic, diastolic, and pulse pressures and aortic distensibility with atrial fibrillation (from the Multi-Ethnic Study of Atherosclerosis). Am J Cardiol 2014; 114: 587-592.

85. Rodriguez CJ, et al. Atrial fibrillation incidence and risk factors in relation to race-ethnicity and the population attributable fraction of atrial fibrillation risk factors: the Multi-Ethnic Study of Atherosclerosis. Ann Epidemiol 2015; 25: 71-76, 6.e1.

86. Bapat A, et al. Relation of Physical Activity and Incident Atrial Fibrillation (from the Multi-Ethnic Study of Atherosclerosis). Am J Cardiol 2015; 116: 883-888.

87. O'Neal WT, et al. Sustained pre-hypertensive blood pressure and incident atrial fibrillation: the Multi-Ethnic Study of Atherosclerosis. J Am Soc Hyperten 2015; 9: 191-196. 
88. Sano F, et al. Heavy alcohol consumption and risk of atrial fibrillation. The Circulatory Risk in Communities Study (CIRCS). Circulation J 2014; 78: 955-961.

89. Nystrom PK, et al. Obesity, metabolic syndrome and risk of atrial fibrillation: a Swedish, prospective cohort study. PloS one 2015; 10: e0127111.

90. Grundvold I, et al. Importance of physical fitness on predictive effect of body mass index and weight gain on incident atrial fibrillation in healthy middle-age men. Am J Cardiol 2012; 110: 425-432.

91. Kokubo Y, et al. Interaction of Blood Pressure and Body Mass Index With Risk of Incident Atrial Fibrillation in a Japanese Urban Cohort: The Suita Study. Am J Hyperten 2015; 28: 1355-1361.

92. Dewland TA, et al. Incident atrial fibrillation among Asians, Hispanics, blacks, and whites. Circulation 2013; 128: 2470-2477.

93. Lindhardsen J, et al. Risk of atrial fibrillation and stroke in rheumatoid arthritis: Danish nationwide cohort study. Br Med J 2012; 344: el257.

94. Ahlehoff $\mathrm{O}$, et al. Psoriasis and risk of atrial fibrillation and ischaemic stroke: Danish Nationwide Cohort Study. Eur Heart J 2012; 33: 2054-2064

95. Pallisgaard JL, et al. Risk of atrial fibrillation in diabetes mellitus: A nationwide cohort study. Eur J Prevent Cardiol 2016; 23: 621-627.

96. Selmer C, et al. The spectrum of thyroid disease and risk of new onset atrial fibrillation: a large population cohort study. Br Med J 2012; 345: e7895.

97. Emilsson L, et al. Increased risk of atrial fibrillation in patients with coeliac disease: a nationwide cohort study. Eur Heart J 2011; 32: 2430-2437.

98. Chiang $\mathrm{CH}$, et al. Herpes simplex virus infection and risk of atrial fibrillation: a nationwide study. Internat J Cardiol 2013; 164: 201-204.

99. Gorenek B, et al. European Heart Rhythm Association (EHRA)/European Association of Cardiovascular Prevention and Rehabilitation (EACPR) position paper on how to prevent atrial fibrillation endorsed by the Heart Rhythm Society (HRS) and Asia Pacific Heart Rhythm Society (APHRS). Europace 2016; Epub ahead of print.

100. Schneider MP, et al. Prevention of atrial fibrillation by Renin-Angiotensin system inhibition a meta-analysis. J Am Coll Cardiol 2010; 55: 2299-2307.

101. Emdin CA, et al. Effect of antihypertensive agents on risk of atrial fibrillation: a meta-analysis of large-scale randomized trials. Europace 2015; 17: 701-710.
102. Rahimi K, et al. Effect of statins on atrial fibrillation: collaborative meta-analysis of published and unpublished evidence from randomised controlled trials. Br Med J2011; 342: d1250.

103. Rapsomaniki E, et al. Blood pressure and incidence of twelve cardiovascular diseases: lifetime risks, healthy life-years lost, and age-specific associations in 1.25 million people. Lancet 2014; 383: 1899-1911.

104. Lokaj P, et al. Pulse Pressure in Clinical Practice. Eur J Cardiovasc Med 2012; 2 Abstract.

105. National Institute for Health and Care Excellence (NICE). Hypertension in adults: diagnosis and management. Available at: https://www.nice.org.uk/guid ance/cg127. Accessed March 1, 2016.

106. Danesh J, et al. The Emerging Risk Factors Collaboration: analysis of individual data on lipid, inflammatory and other markers in over 1.1 million participants in 104 prospective studies of cardiovascular diseases. Eur J Epidemiol 2007; 22: 839-869.

107. Denaxas SC, et al. Data resource profile: cardiovascular disease research using linked bespoke studies and electronic health records (CALIBER). Internat J Epidemiol 2012; 41: 1625-1638.

108. Montori VM, et al. Optimal search strategies for retrieving systematic reviews from Medline: analytical survey. Br Med J 2005; 330: 68.

109. Kwon Y, et al. An assessment of the efficacy of searching in biomedical databases beyond MEDLINE in identifying studies for a systematic review on ward closures as an infection control intervention to control outbreaks. System Rev 2014; 3: 135.

110. Stevinson C, Lawlor DA. Searching multiple databases for systematic reviews: added value or diminishing returns? Complement Therap Med 2004; 12: 228-232.

111. Lemeshow AR, et al. Searching one or two databases was insufficient for metaanalysis of observational studies. J Clin Epidemiol 2005; 58: 867-873.

112. Horton R. The less acceptable face of bias. Lancet 2000; 356: 959-960.

113. Nelson CP, Hamby SE, Saleheen D, et al. Genetically determined height and coronary artery disease. N Engl J Med 2015; 372: 1608-1618. 